\title{
The Effect of Nurses' Virtual Learning on Knowledge and Practice of Observing X-Ray Protection Principles
}

\section{Marzieh Hasanian ${ }^{1,}$ Nastaran Karami $^{2}$, Mehdi Molavi Vardanjani ${ }^{3 *}$, Leili Tapak ${ }^{4}$}

1. Assistant Professor, Research Center for Chronic Diseases (Home Care), Hamadan University of Medical Sciences, Hamadan, Iran

2. Graduate Student, Nursing Student Research Center, Hamadan University of Medical Sciences, Hamadan, Iran

3. Instructor, Chronic Disease Research Center (Home Care), School of Nursing and Midwifery, Hamadan University of Medical Sciences, Hamadan, Iran

4. Assistant Professor, Department of Biostatistics, School of Public Health, Hamadan University of Medical Sciences, Hamadan, Iran

\section{Article Info \\ Received: 2019/07/14; \\ Accepted: 2019/08/28; \\ Published Online: 2020/04/07 \\ 10.30699/ajnmc.28.1.46}

Original Article

Use your device to scan and read the article online

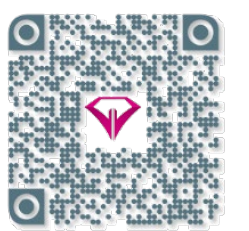

\section{ABSTRACT}

Introduction: Increasing the level of knowledge about X-ray protection can play an important role in reducing the effects of radiation. The aim of this study was to investigate the effect of virtual education of nurses on adherence to X-ray protective principles.

Methods: This study was a randomized clinical trial on 90 nurses. Educational intervention was virtualized through social network. Questionnaires were completed before and after the intervention in both groups and the data were analyzed by paired and independent t-test using SPSS 24.

Results: The mean and standard deviation of the level of protection against $\mathrm{x}$ rays in the intervention group before and after the intervention were $15.84 \pm 3.64$, $30.2 \pm 26.3$ and in the control group before and after the intervention was $14.08 \pm 4.45,48.14 \pm 4.27$, respectively. Mean and standard deviation of nurses' performance score before and after intervention in the intervention group were $2.8 \pm 1.03,5.62 \pm 0.96$ and $3.82 \pm 1.07,3.93 \pm 1.03$ in the control group before and after the intervention, respectively. The results of paired and independent t-test showed that the mean of performance and the mean score of nurses' knowledge about the application of the principles of X-ray protection before and after the intervention in the intervention group were significantly different; the mean score of nurses' performance and knowledge after intervention was increased $(P=0.000)$.

Conclusion: Learning based on cyberspace increases the level of protection knowledge and the performance of nurses against X-rays.

Keywords: Virtual learning, Knowledge, Performance, X-ray protection, Nurse
Corresponding Information:
Mehdi Molavi Vardanjani, Instructor, Chronic Disease Research Center (Home Care), School of Nursing and Midwifery, Hamadan University of Medical Sciences, Hamadan, Iran. Email: m.molavi@umsha.ac.ir

Copyright $(C 2020$, This is an original open-access article distributed under the terms of the Creative Commons Attribution-noncommercial 4.0 International License which permits copy and redistribution of the material just in noncommercial usages with proper citation.

\section{How to Cite This Article:}

Hasanian M, Karami N, Molavi vardanjani M, Tapak L. The Effect of Nurses' Virtual Learning on Knowledge and Practice of Observing X-Ray Protection Principles. Avicenna J Nurs Midwifery care. 2020; 28 (1) :46-55 
تأثير آموزش مجازى يرستاران بر دانش و عملكرد رعايت اصول حفاظتى در برابر يرتو ايكس

مرضيه حسنيان'، نسترن كرمى '، مهدى مولوى وردنجانى بّ"، ليلى تاياى

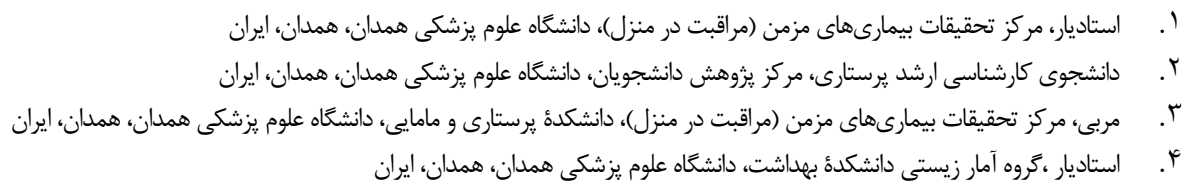

\begin{tabular}{|c|c|}
\hline קكيده & اطلاعات مقاله \\
\hline 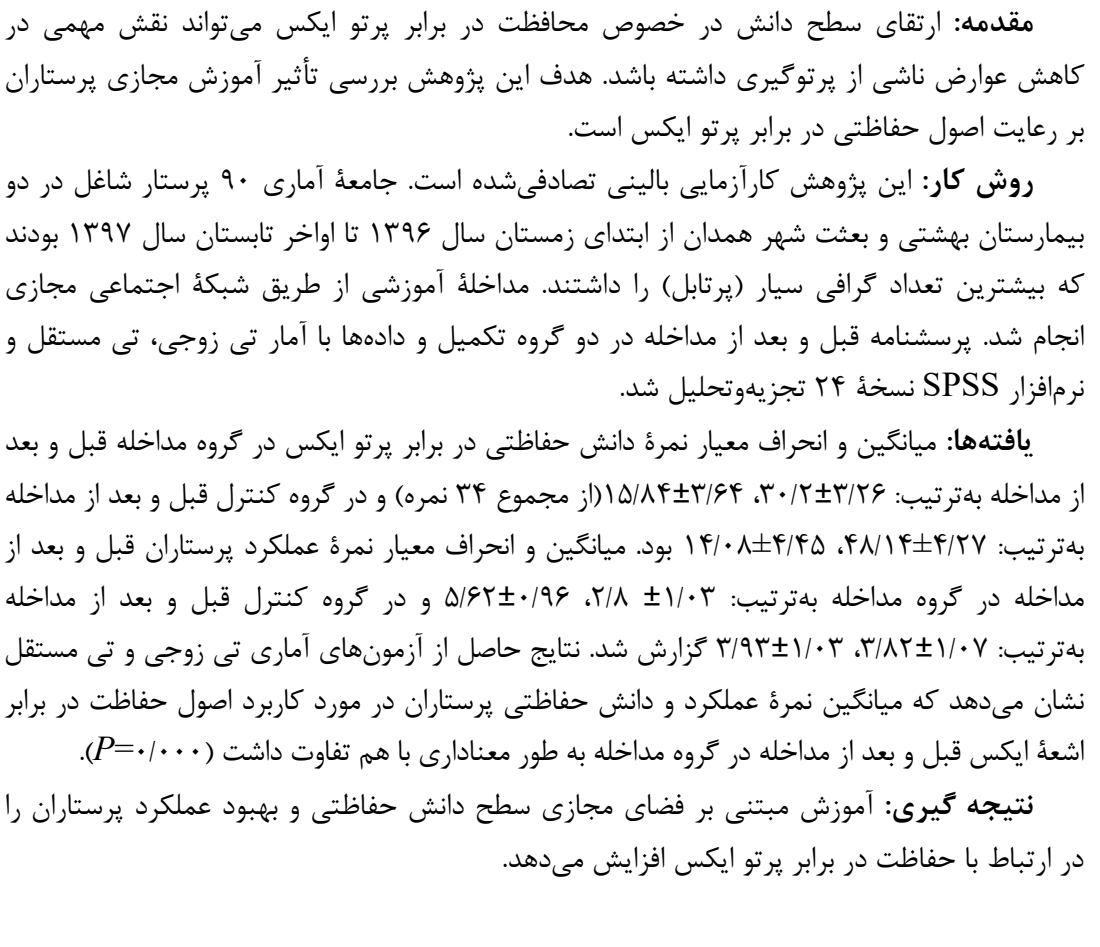 & 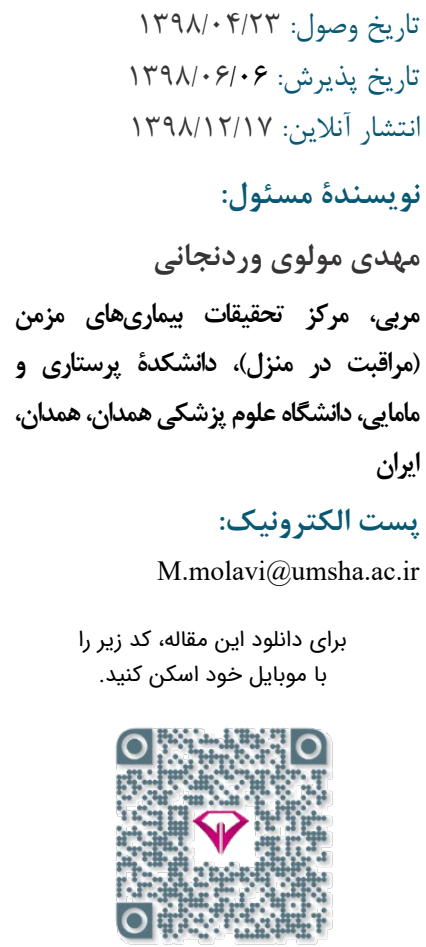 \\
\hline كليدوازهها: آموزش مجازى، دانش، عملكرد، يرتو ايكس، برستار & \\
\hline
\end{tabular}

مقدمه

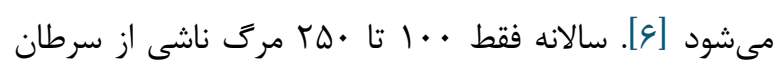

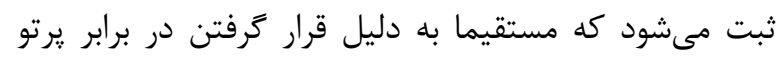

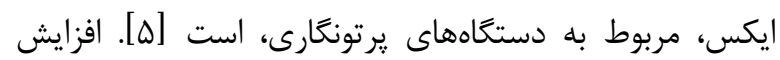

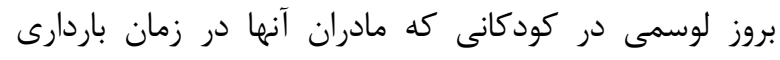

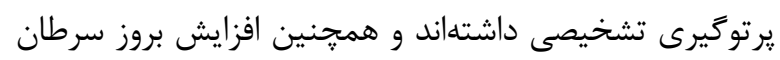

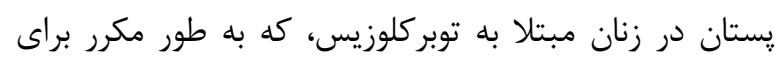

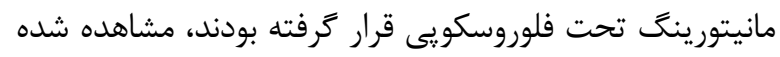

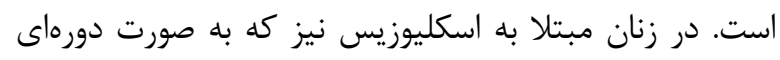

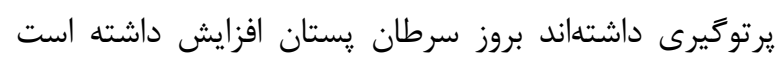

امروزه استفاده از يرتو ايكس در علم يزشكى به ييشرفتهاى عمده در تشخيص و درمان بسيارى از بيمارى برها

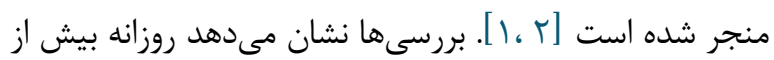

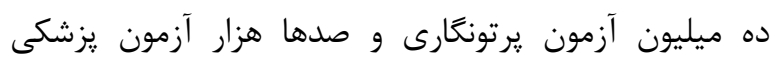

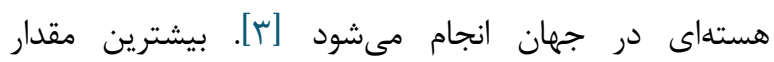

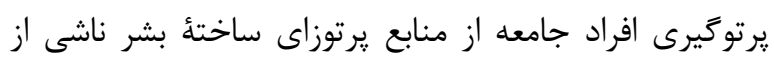

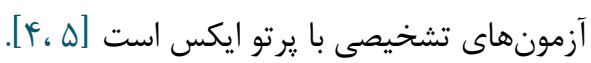

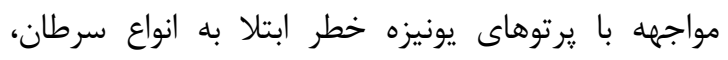

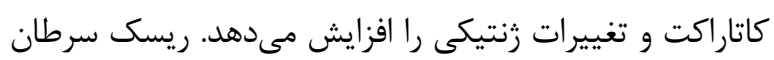

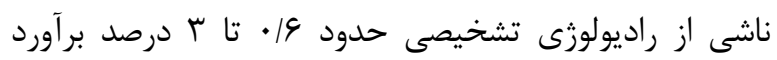


استفاده از شبكههاى اجتماعى مجازى در جهان در حال افزايش است. بهرغم ظرفيتها و قابليتهاى شبكههاى اجتماعى مختلف براى توسعه فضاهاى آموزشى كشور كاربرد

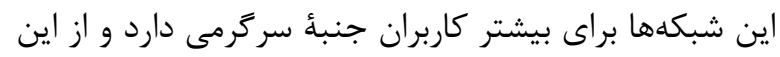
فضا براى هدفهاى آموزشى به نحو مطلوب استفاده نشده

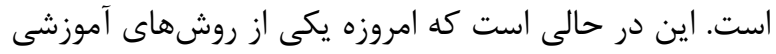

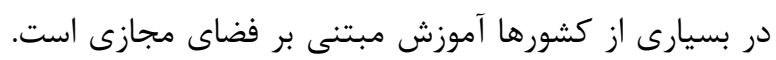
Kadivar بر توانايى مراقبتى يرستاران مراقبتهاى ويزٔه نوزادان مؤثر

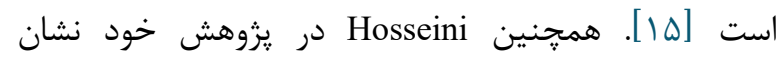
مىدهد كه آموزش الكترونيك در آموزش و ارتبن ارتقاى دانش

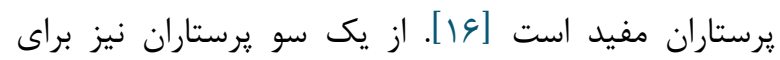

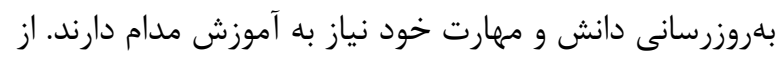

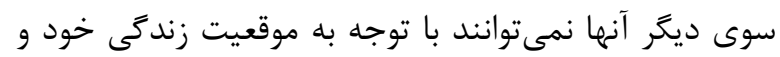
حجم كارى فراوان آموزش سنتى را به طور مدام دريافت بند

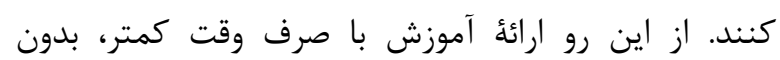

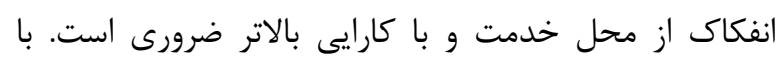

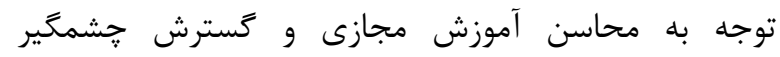

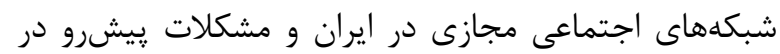

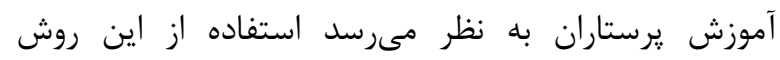

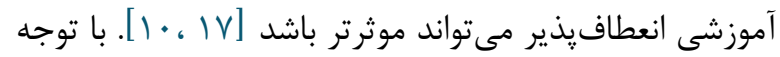

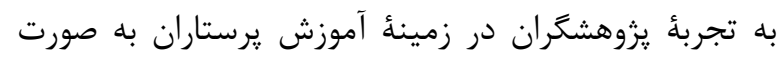

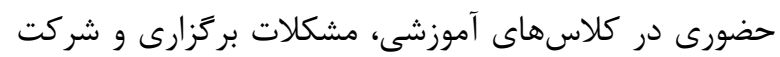

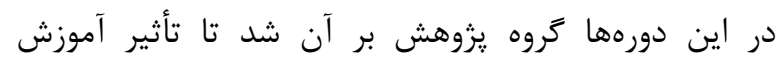

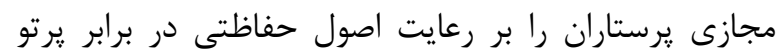

$$
\text { ايكس بررسى كند. }
$$

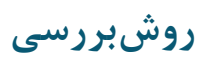

اين يزوهش از نوع كارآزمايى بالينى دوگروهى با طرح

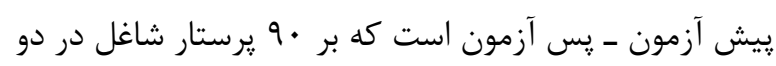

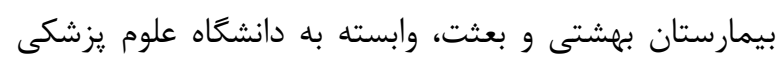

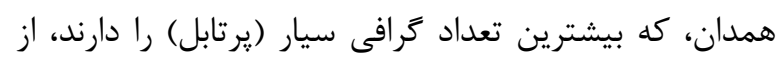

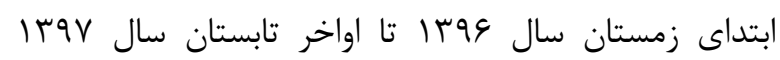

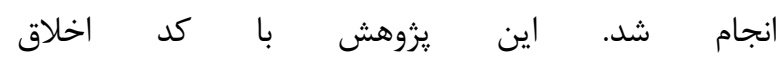

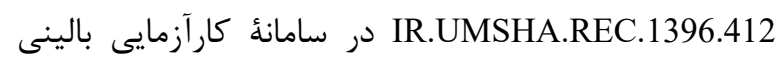

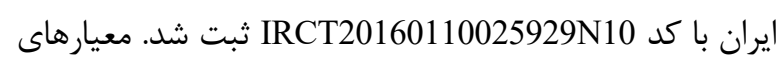
ورود به يزوهش شامل: داشتن حداقل مدرى كارش بناسى، شاغل بودن در بخشهاى تحت مواجهه با كرافى سيار و يرتو
محافظت جدى از كاركنان و بيماران، به دليل وجود برتو ايكس و ديكر عوامل خطرناك موجود در بيمارستان، ضرورى

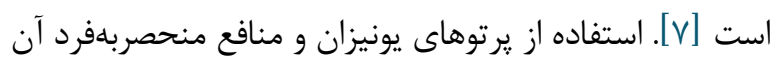

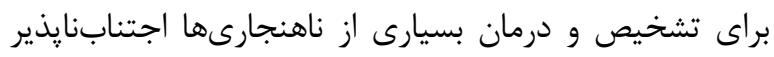

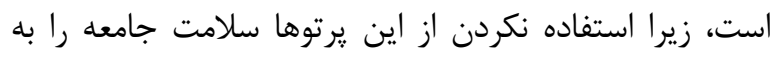

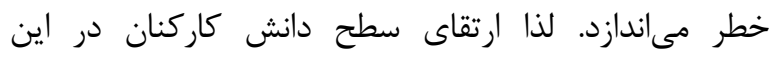

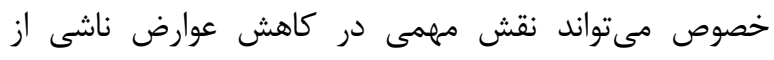
يرتوكيرى در سطح جامعه داشته باشد [هان.

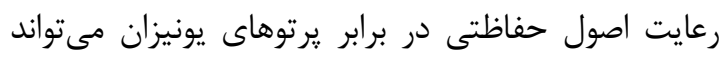

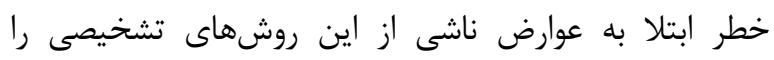

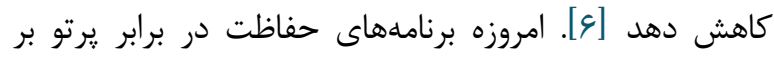

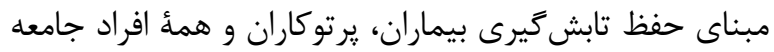
بر اساس اصل As Low As Reasonably (ALARA) Achievable

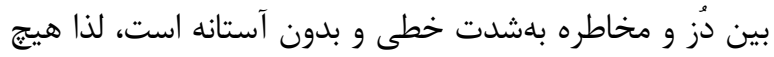

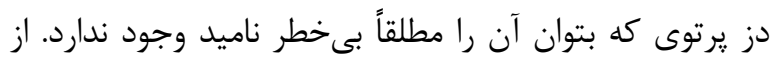

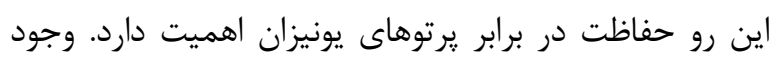

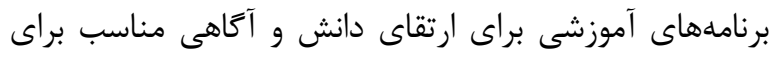

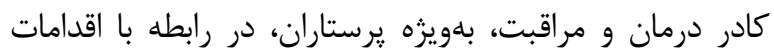

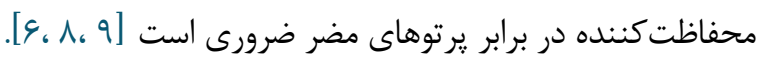

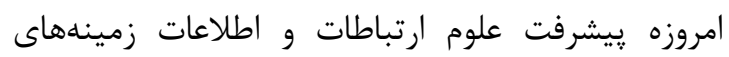

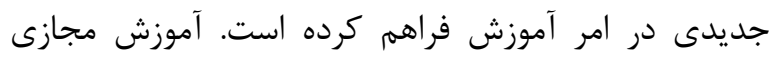

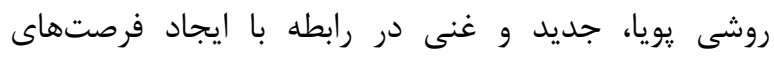

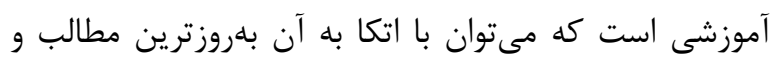

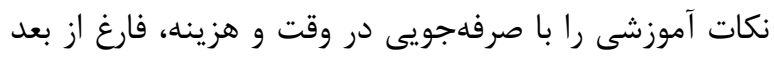

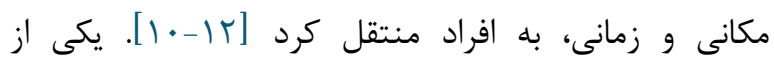
روشهاى آموزش استفاده از شبكههاى اجتماعى مجازى مانى

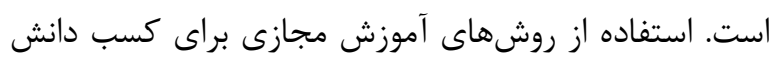

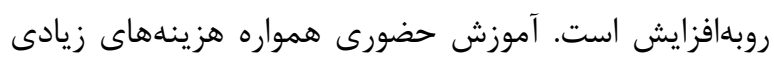

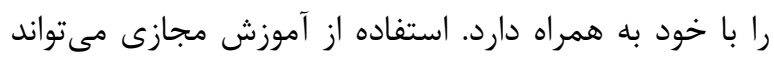

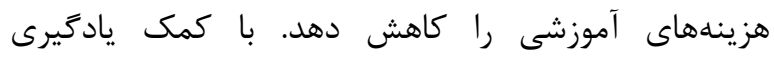

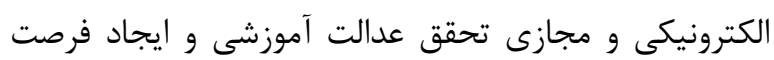

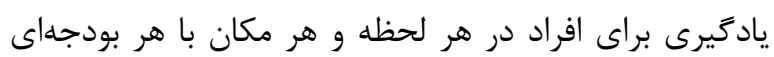

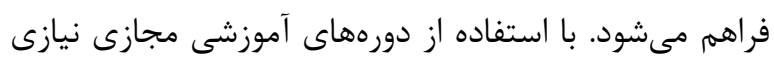

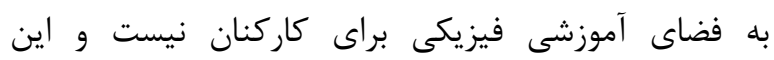

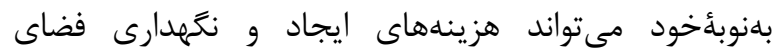

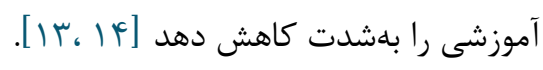


ايمنى در برابر يرتو ايكس با مشاهدة رفتارشان در زمان

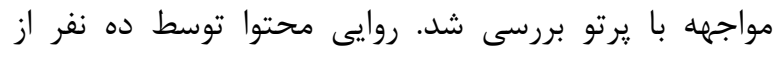

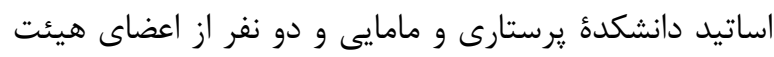

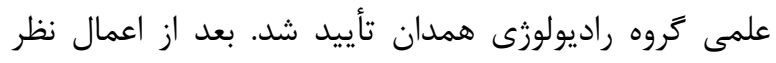

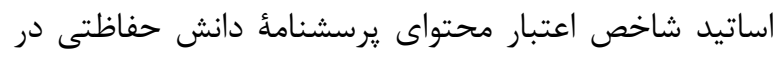

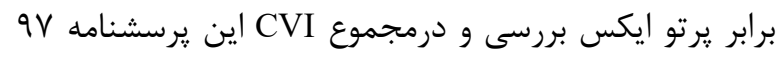

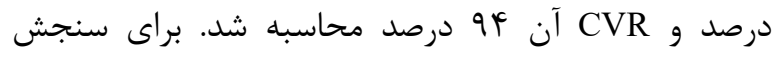

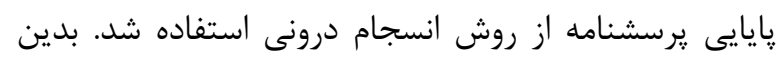

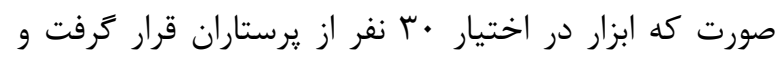

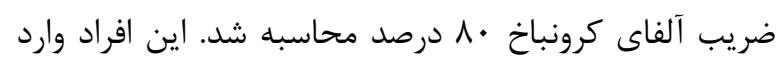

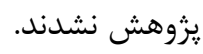
براى سنجش عملكرد از يرسشنامئ محققساخته استفاده

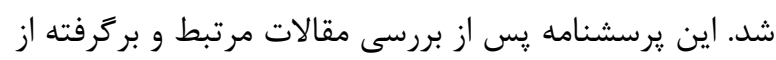

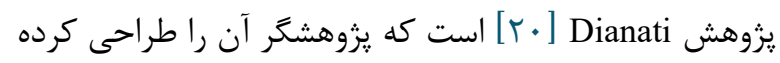

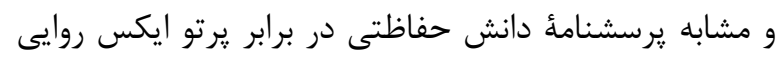

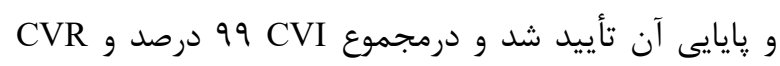

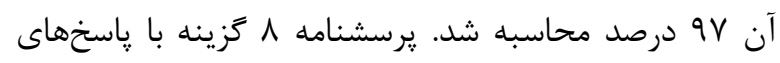

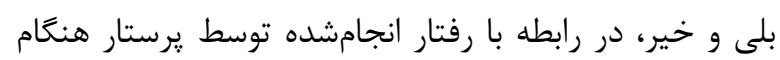

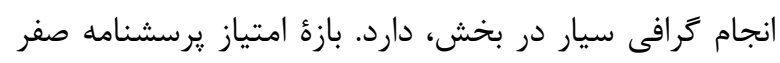

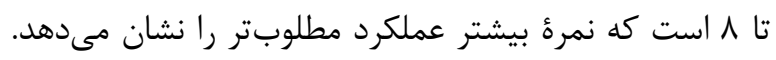

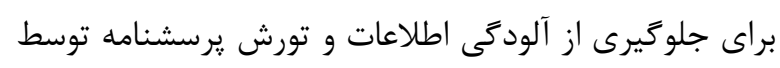

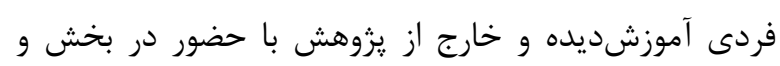

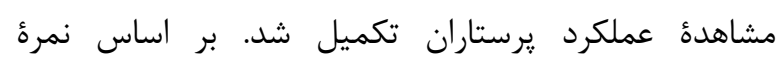

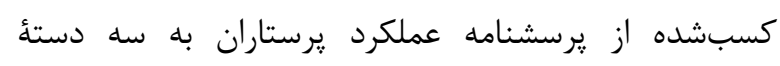

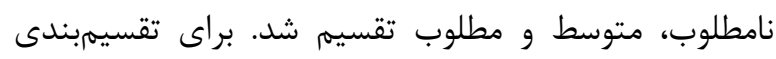

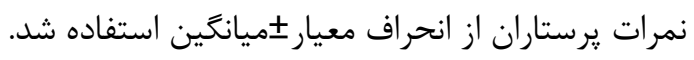

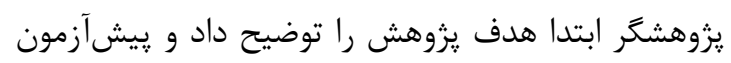

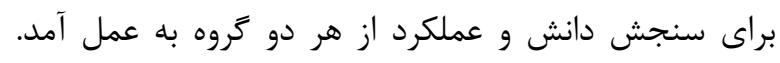

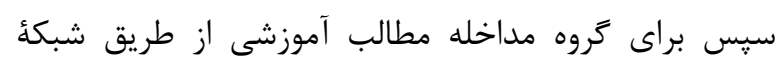

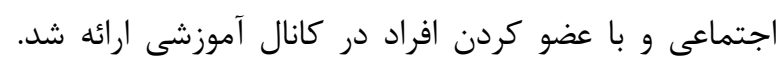

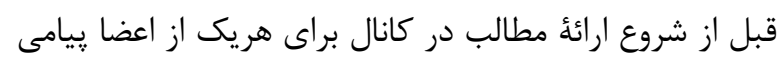

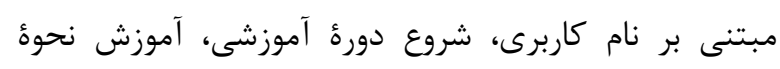

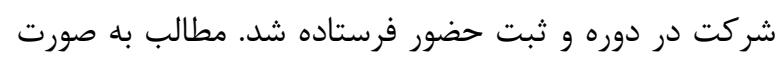

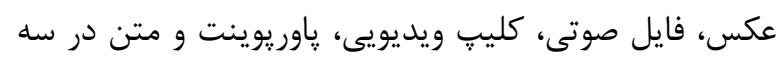

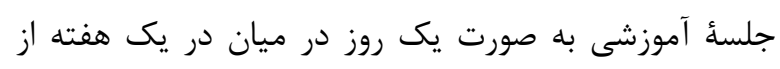

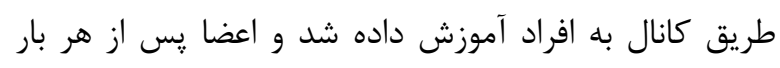

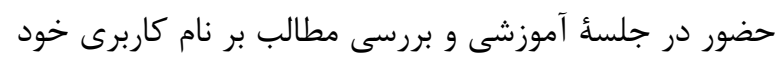

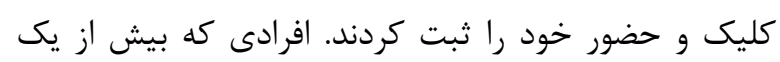

ايكس (ارتويدى و بخشهاى مراقبتهاى ويزه)، سابقه كار

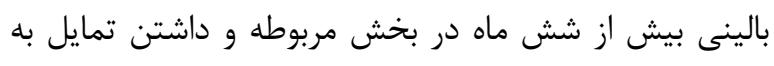

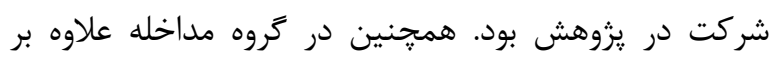

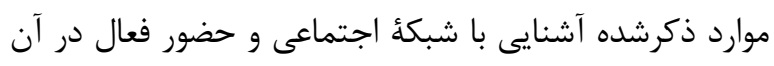

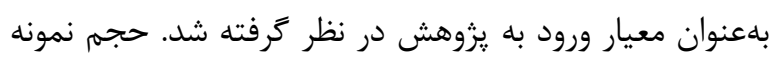

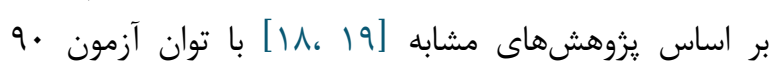

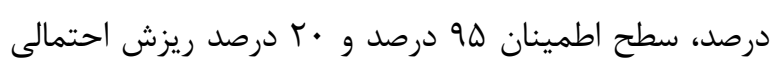

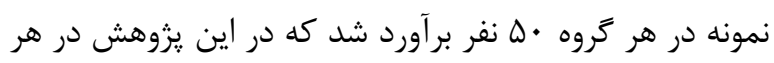

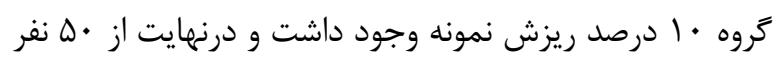

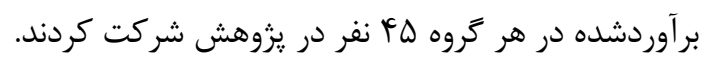

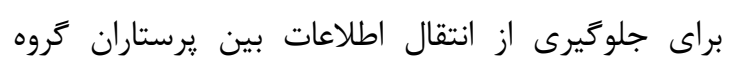

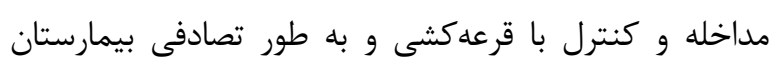

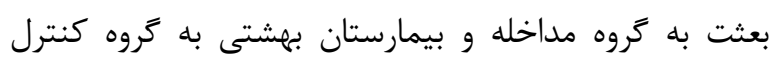

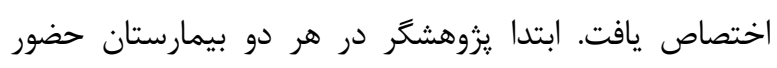

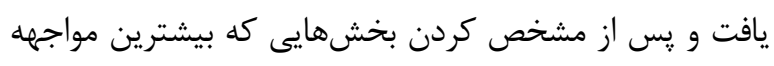

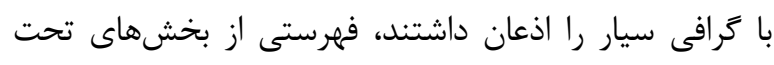

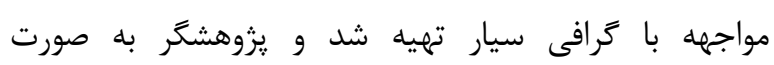

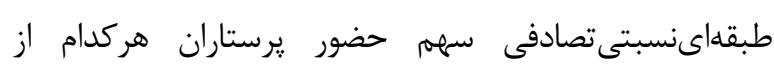

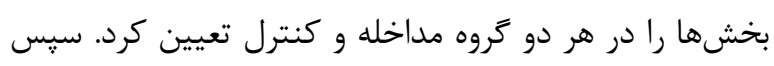

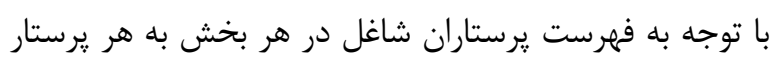

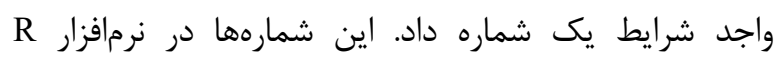

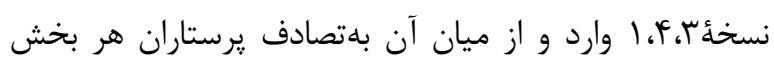
براى ورود به يزوهش تعيين شدند.

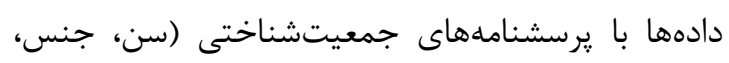

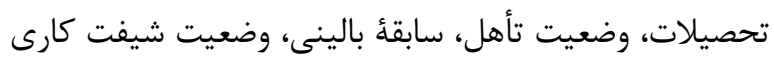

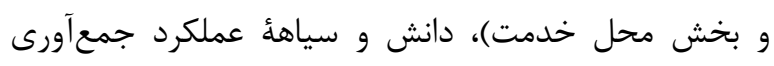

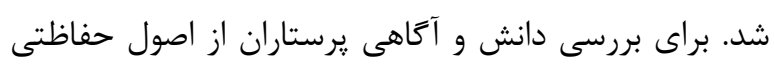

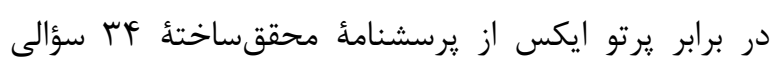

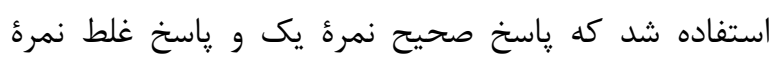

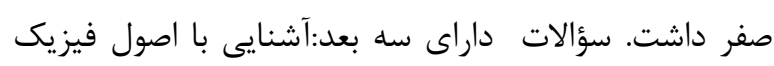

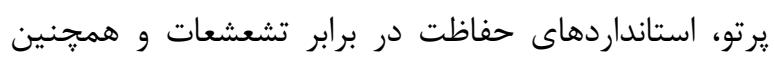

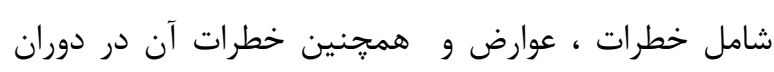

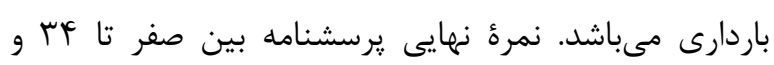

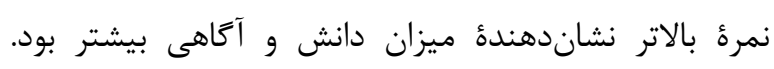

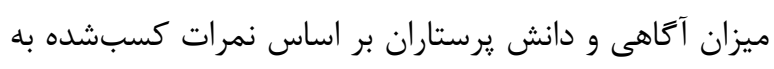

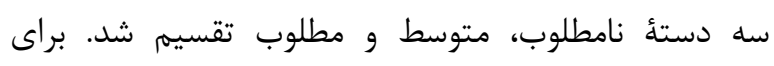
تقسيمبندى نمرات يرستاران از ميزان انحراف معيار ذميانكَين

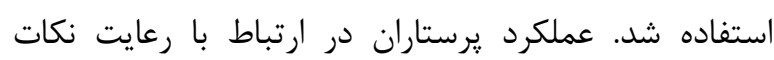




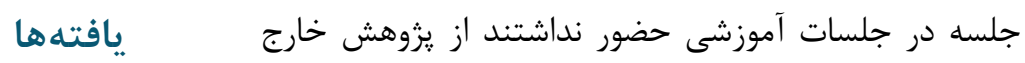

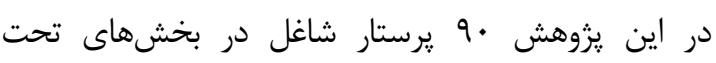
شدند. در جلسهٔ اول يس از معرفى مطالب در رابطه با ماهيت

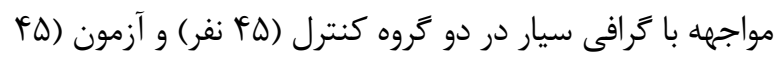

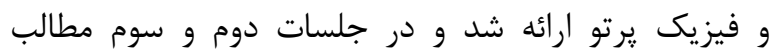

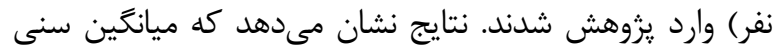
بلترتيب در رابطه با استانداردهاى حفاظتى در در برابر درابر افراد شركت كننده در يزوهش

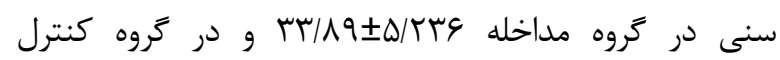
تشعشعات و عوارض يرتو ايكس ارائه شد. پِ إز ازئ يك ماه

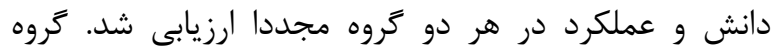

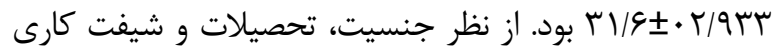

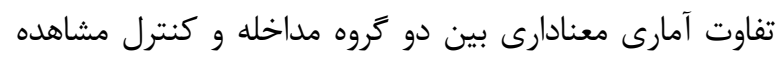

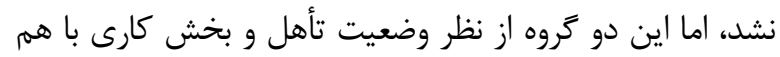

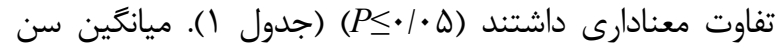
كروه مداخله بيشتر از ميانكين سن كروه كنترل بود و اين تفاوت (جنات

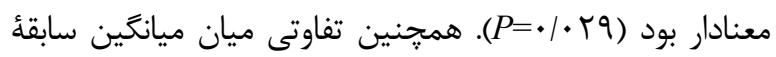

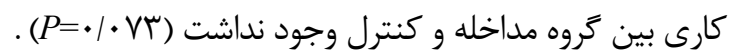

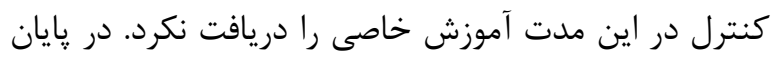
يس از انجام يسآزمون يزوهشكر اعضاى كروه كنترل ران رانيز عضو كانال آموزشى كرد و مطالب راد در اختيار آنها قرار داد.

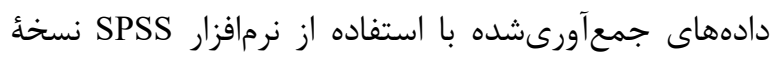

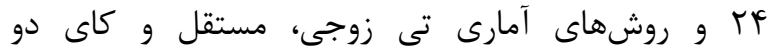
تجزيهوتحليل و ه • • P Pعنادار در نظر كرفته شد. همجنين دو كروه همخن و دادهها نرمال بود. جدول ا. توزيع فراوانى و خصوصيات دموكرافيك كيفى در هر دو كروه مداخله و كنترل

\begin{tabular}{|c|c|c|c|c|}
\hline P-value & آمارة آزمون كاى دو & فراوانى (دروه كنترل & $\begin{array}{l}\text { فرواوه مداخلى (درصد) } \\
\text { فراخله }\end{array}$ & اطلاعات دموكرافيك \\
\hline \multirow{3}{*}{$\cdot / \mathrm{VA}$} & \multirow{3}{*}{$\cdot 1 \cdot V$} & & & جنسيت \\
\hline & & $(\mid \mathrm{V} / \backslash \wedge) \wedge$ & $(Y \cdot)^{9}$ & 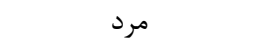 \\
\hline & & $(\Lambda T) r V$ & $(\Lambda \cdot){ }^{\mu}$ & زن \\
\hline \multirow{3}{*}{$\cdot 1 \cdot 1$} & \multirow{3}{*}{$9 / 10$} & & & وضعيت تأهل \\
\hline & & $(\mathcal{F} / \mathcal{F}) r$. & $(Y \cdot)^{9}$ & مجرد \\
\hline & & $(\Delta \Delta / \varepsilon) r \Delta$ & 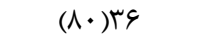 & متأهل \\
\hline \multirow{3}{*}{$\cdot 199$} & \multirow{3}{*}{$\cdot / 10$} & & & تحصيلات \\
\hline & & $(q T / T) F T$ & $(91 / 1) 41$ & كارشناسى \\
\hline & & $(\varepsilon / V) r$ & $(\Lambda / 9)^{F}$ & كارشناسى ارشد \\
\hline \multirow{5}{*}{$\cdot 119$} & \multirow{5}{*}{$\uparrow / 9 \wedge \varphi^{*}$} & & & شيفت كارى \\
\hline & & $(1) / 1) \Delta$ & $(Y Y / T)) \cdot$ & صبح \\
\hline & & $(\varepsilon / V) r$ & $(1) / 1) \Delta$ & عصر \\
\hline & & $(\varepsilon / V) r$ & $(\cdot) \cdot$ & شب 1 \\
\hline & & $(V \Delta / \bar{Q}) M Y$ & $(\varphi g / V) \Gamma \cdot$ & شيفت در گردش \\
\hline \multirow{5}{*}{$\cdot 1 \cdots$} & \multirow{5}{*}{ rr/А9)* } & & & بخش \\
\hline & & $(\cdot) \cdot$ & $(11 / 1) \Delta$ & ارتويدى \\
\hline & & $(\cdot) \cdot$ & $(T \cdot)^{9}$ & NICU \\
\hline & & $(1 \cdots) \& \Delta$ & $(\varepsilon \cdot) Y V$ & ICU \\
\hline & & $(\cdot) \cdot$ & $(\Lambda / 9)^{\mathrm{F}}$ & PICU \\
\hline
\end{tabular}


درصد يرستاران در ₹روه مداخله بعد از مداخله وضعيت

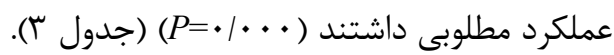
با توجه به نتايج اين يزوهش بين ميانگين نمره عملكرد

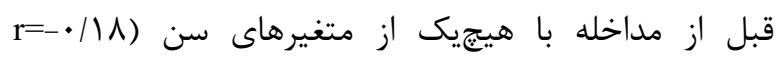

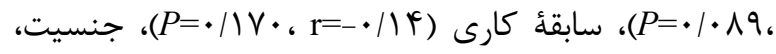

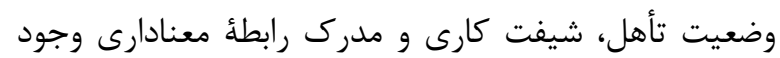

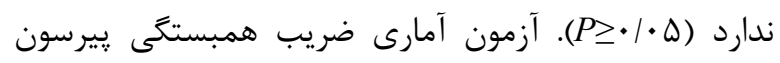
نشان مىدهد كه بين ميانگين نمره دانش حفاظتى قبل از مداخله در افراد با متغير سابقه كارى، رابطهُ مستقيم و

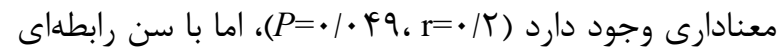

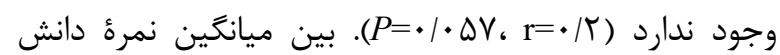
حفاظتى قبل از مداخله و مدرك رابطةٌ معنادارى وجود دارد، به طورى كه در افراد با مدرك كارشناسى ارشد ميانگين نمره

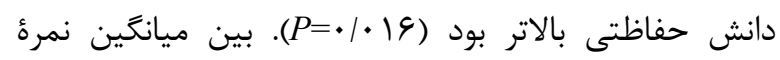
دانش حفاظتى قبل از مداخله با جنسيت، وضعيت تأهل و

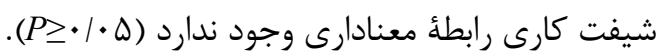

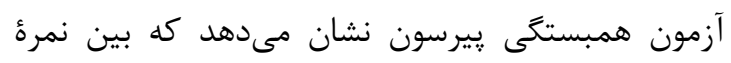

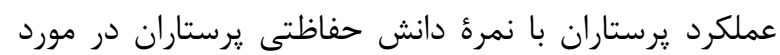

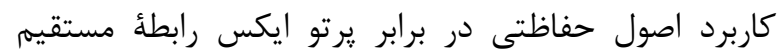

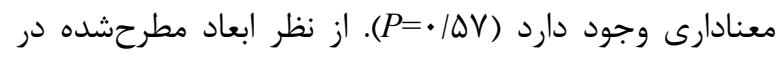
يرسشنامة دانش حفاظتى تفاوت معنادارى بين دو گروه مداخله و كنترل در بعد دانش فيزيك يرتو (P

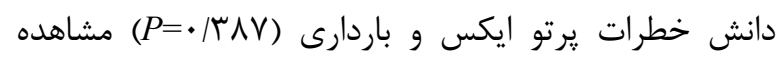

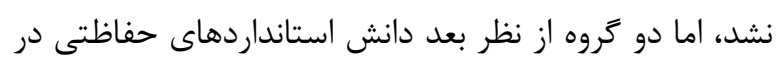

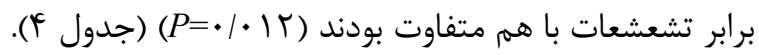

ميانگين دانش حفاظتى گرستاران در مورد كاربرد اصول حفاظت در برابر يرتو ايكس بعد از مداخله در گروه مداخله به

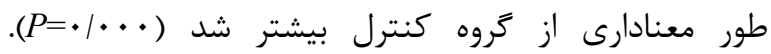
همجنين نتايج يزوهش افزايش سطح ميانگين نمره عملكرد يرستاران را در مورد كاربرد اصول حفاظت در برابر :يرتو ايكس بعد از انجام آموزش در زروه مداخله نشان ميىدهد.

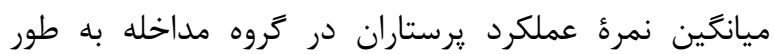

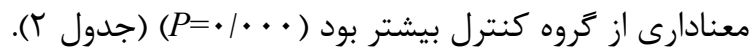

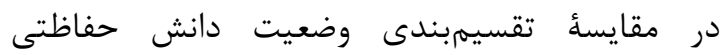
يرستاران در مورد كاربرد اصول حفاظت در برابر ڤيرتو

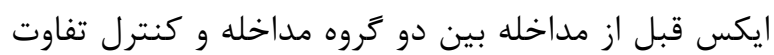

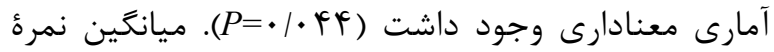
دانش حفاظتى گروه مداخله بيشتر از زروه ورود كنترل بود.

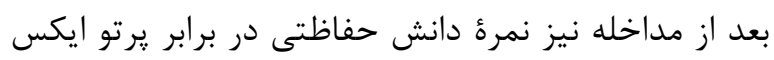
بين دو گروه مداخله و كنترل تفاوت معنادارى داشت

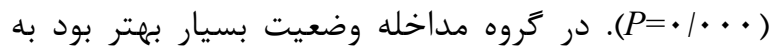

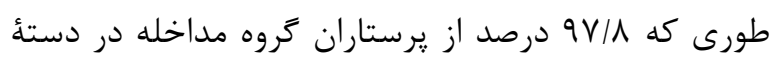

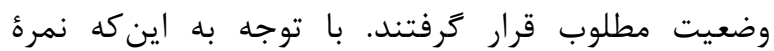
عملكرد و حفاظت قبل از مداخله بين دو گروه تفاوت معنادارى داشت و همجنين دو گروه از نظر ميانگين سنى و وضعيت تأهل همسان نبودند، لذا براى كنترل اثر مخدوش كنندگى دو متغير نمره قبل از آزمون و سن تأهل

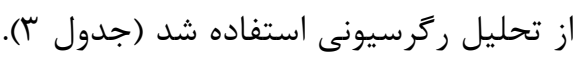
در تقسيمبندى وضعيت عملكرد بعد از مداخله هيجيك از گروههاى مداخله و كنترل وضعيت عملكرد نامطلوبى نداشتند و بين دو گروه تفاوت آمارى معنادار وجود داشت.

جدول r. مقايسهٔ ميانكين و انحراف معيار نمرهُ دانش و عملكرد يرستاران قبل و بعد از مداخله در دو كروه مداخله و كنترل

\begin{tabular}{|c|c|c|c|c|c|c|}
\hline \multirow[t]{2}{*}{ P-value } & \multirow[t]{2}{*}{$\mathbf{t}$} & 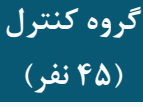 & \multicolumn{3}{|c|}{ 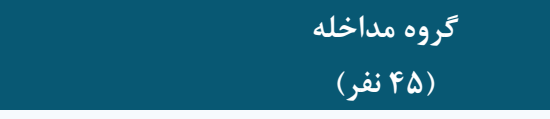 } & \multirow[t]{2}{*}{ متغير ها } \\
\hline & & ميانغين & انحراف معيار & ميانغين & انحراف معيار & \\
\hline & & & & & & دانش حفاظتى \\
\hline $.1 \cdot \operatorname{tg}$ & $r \cdot / 4 \varepsilon$ & $\mid f / \cdot \Lambda$ & $F / F \Delta$ & $\mid \Delta / A F$ & $1 / \cdot r$ & قبل از مداخله \\
\hline \multirow[t]{2}{*}{$\cdot|\cdot \cdot|^{* * *}$} & $\mid 14 / 94$ & $\mid F / F \lambda$ & $F / T V$ & $r \cdot / r$ & .199 & بعد از مداخله \\
\hline & & & & & & عملكرد حفاظتى \\
\hline$\cdot 1 \cdot \cdots 1$ & $-F / \varepsilon$. & T/AT & $1 / \cdot V$ & $r / \Lambda$ & r/q & قبل از مداخله \\
\hline$\cdot /\left.\cdots\right|^{*}$ & $r q / 4 V$ & r/q & $1 / \cdot r$ & D/AT & T/TQ & بعد از مداخله \\
\hline
\end{tabular}

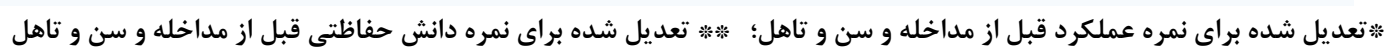


ارتقاى سطح دانش يرستاران از عوامل مؤثر در رعايت هرجه بهتر اصول حفاظتى در برابر يرتو ايكس است كه با نتايج

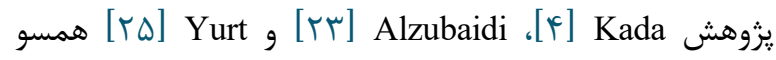

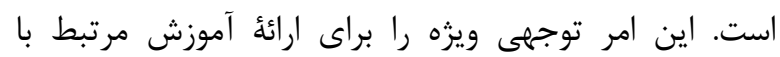
ماهيت يرتو ايكس و اصول حفاظتى در برابر تشعشعات نشان

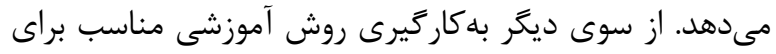

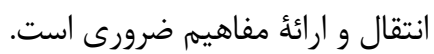

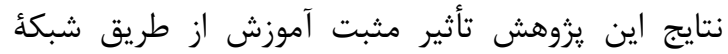

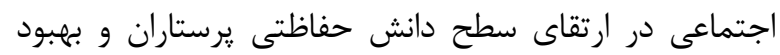

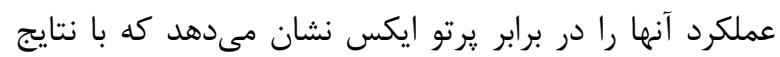

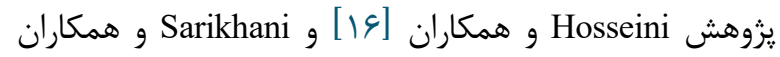

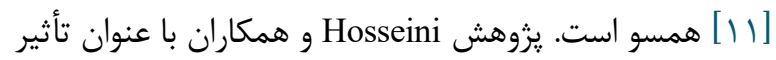

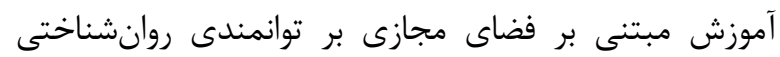

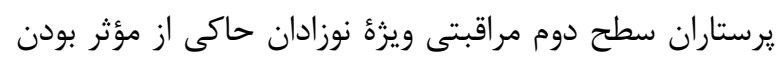

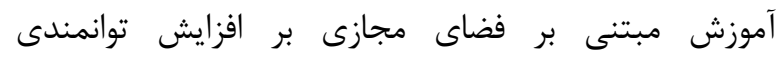

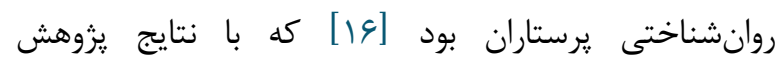
Nasteizaei به دليل تفاوت در نوع آموزش نوين و مجازى بهكاركَفتهشده،

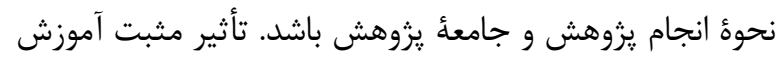

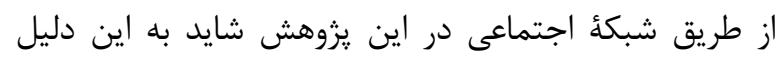

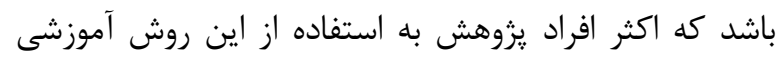

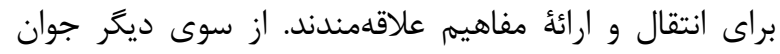

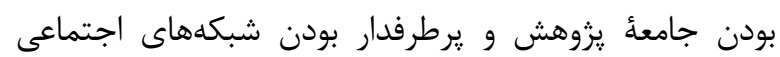

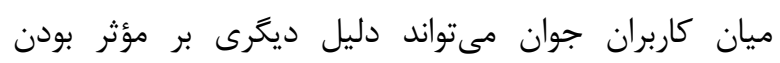
بهكارگيرى اين روش آموزشى در ارائه مفاهيم باشد.

\section{نتيجه كيرى}

با توجه به يافتههاى يزوهش و اهميت دانش و عملكرد

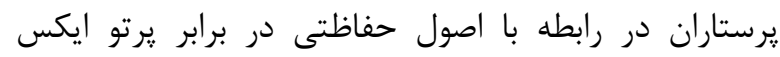

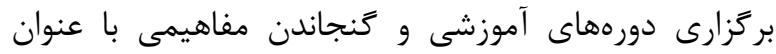
حفاظت در برابر تشعشعات در دروس رشتأ يرستارى ضرورى

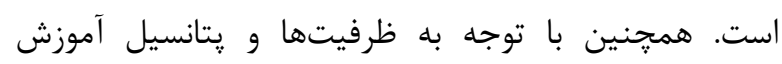

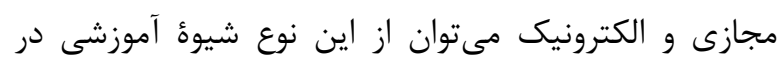

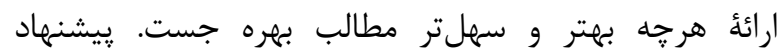

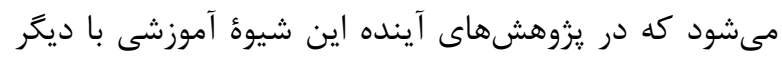

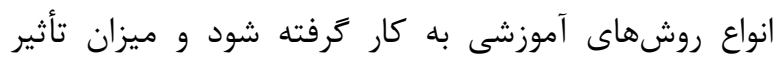
هر كدام از روشها در انتقال بهتر مطالب ارزيابى شود.
تفاوت شركت كنندكان در يزوهشها وتفاوت ابزار

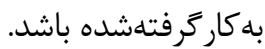

يزوهش Luntsi و همكاران [N] دانش مناسب و مطلوب يرستاران را در رابطه با اصول حفاظتى در برابر يرتو نشان

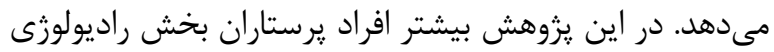

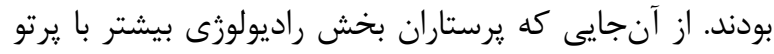

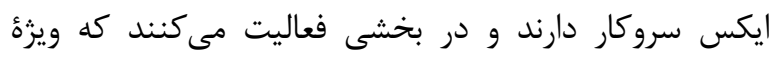

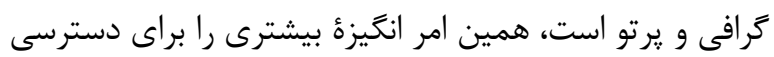

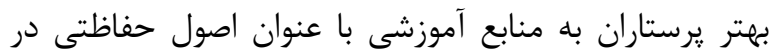

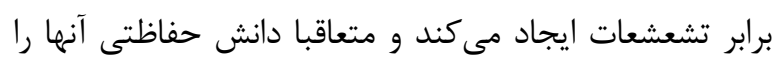
افزايش مىدهد. دانش متوسط و ضعيف يرستاران مىتواند به دليل محدود بودن آموزشهاى قبل از فارغالتحصيلى و نبود

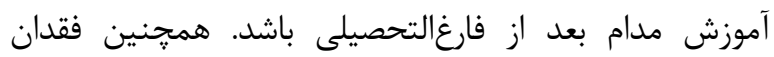

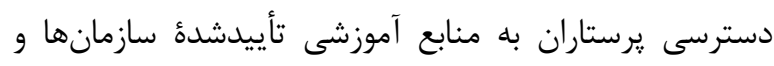
نهادهاى بينالمللى، كه به طور اختصاصى اصول حفاظتى در

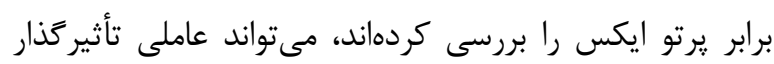

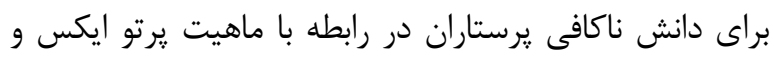
رعايت اصول حفاظتى در برابر آن باشد.

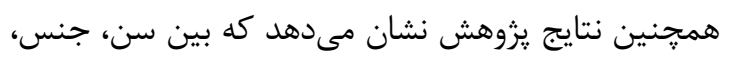

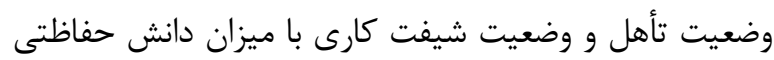

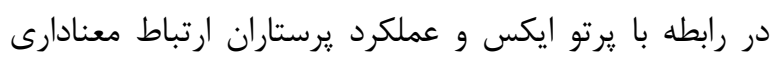

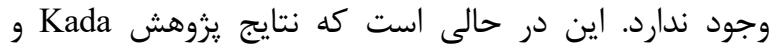

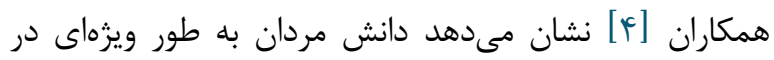

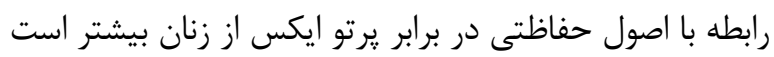

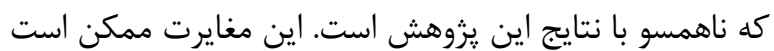

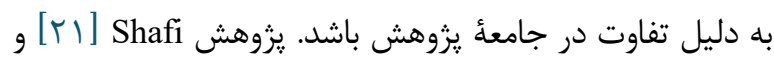
[ه] Oudi بين دانش حفاظتى در ارتباط با يرتو ايكس با سن و جنسيت

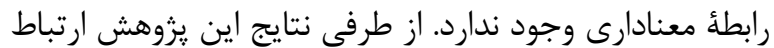
مثبت و مستقيم سطح تحصيلات و سابقهُ بالينى را با ميزان

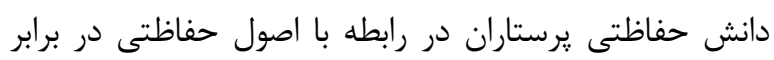

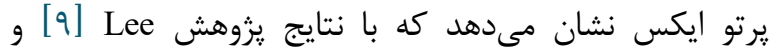
Alzubaidi Urushizaka تحصيلات با ميزان دانش حفاظتى در برابر يرتو ايكس يافت

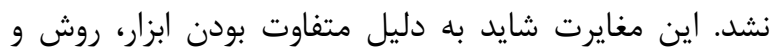

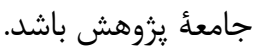




$$
\text { كاركنان بيمارستان هاى شهيد بهشتى و بعثت همدان تشكر }
$$

\section{References}

1. Chinangwa G, Amoako JK, Fletcher JJ. Investigation of the Status of Occupational Radiation Protection in Malawian Hospital. Malawi Medical Journal. 2018;30(1):22-4. [DOI:10.4314/mmj.v30i1.5] [PMID] [PMCID]

2. Anim-Sampong S, Opoku SY, Addo P, Botwe BO. Nurses Knowledge of Ionizing Radiation and Radiation Protection During Mobile Radiodiagnostic Examinations. Educ Res. 2015 Apr;6:39-49.

3. Karami V, Zabihzadeh M. Radiation Protection in Diagnostic X-ray Imaging Departments in Iran: A Systematic Review of Published Articles. Journal of Mazandaran University of Medical Sciences. 2016 Apr 15;26(135):175-88.

4. Kada S. A Study of General Practitioners' Knowledge of Ionizing Radiation from Diagnostic Imaging Examinations. Quality in primary care. 2010;18(6):3917.

5. Oudi D, Kianfar S. Nursing Staff and Students' Knowledge About Medical Imaging Methods in Birjand University of Medical Sciences. Modern Care Journal. 2013;10(2).108-14.

6. Karami V, Zabihzadeh M. Review On Radiation Protection in Diagnostic Radiology. Tehran University Medical Journal TUMS Publications. 2016 Oct 15;74(7):457-66.

7. Kalantari A, khosrovani S. State of observing Radiology standards Shahid Beheshti Hospital of Yasouj .Armaghan danesh Journal of Medical Science. 2013;88(19):421-32. .[Persian]

8. Luntsi G, Ajikolo AB, Flaviuos NB, Nelson L, Nwobi C, Hassan JM, Malgwi FA. Assessment of Knowledge and Attitude of Nurses Towards Ionizing Radiation During Theatre/Ward Radiography. J Nurs Care. 2016; 5(3):342-5. [DOI:10.4172/2167-1168.1000342]

9. Lee WJ, Woo SH, Seol SH, Kim DH, Wee JH, Choi SP, Jeong WJ, Oh SH, Kyong YY, Kim SW. Physician and Nurse Knowledge About Patient Radiation Exposure in the Emergency Department. Nigerian journal of clinical practice. 2016;19(4):502-7. [DOI:10.4103/1119-3077.183298] [PMID]

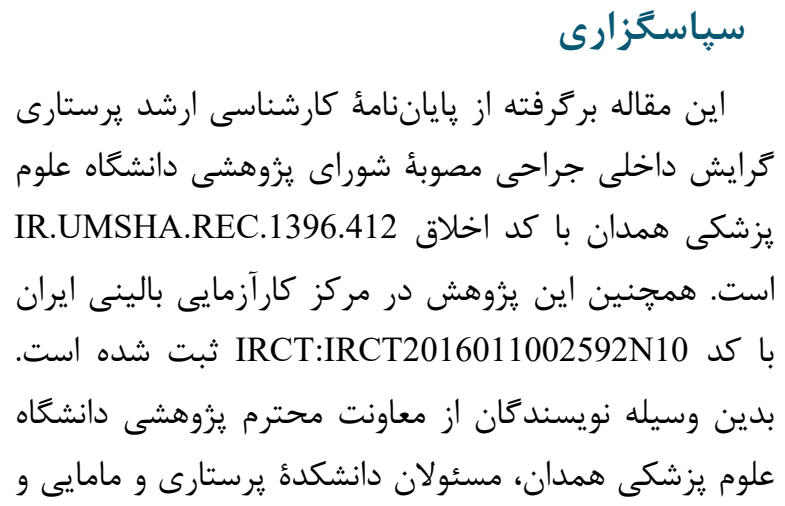

10. Kadivar M, Seyedfatemi N, Zolfaghari M, Mehran A. The Impact of Virtual-Based Educationon Nurses' SelfEfficacy in the Level II Neonatal Care. Crit Care Nurs J. 2016 Nov 10;9(4):1-7. [DOI:10.17795/ccn-9281]

11. Sarikhani R, Moosavipour S, Feizabadi N, Zare M. Effect of Virtual Social Networks on Nursing Students' English Learning. Interdisciplinary Journal of Virtual Learning in Medical Sciences. 2016;7(4). [DOI:10.5812/ijvlms. 10413]

12. Lahti $M$, Hätönen $H$, Välimäki $M$. Impact of $E$ Learning on Nurses' and Student Nurses Knowledge, Skills, and Satisfaction: A Systematic Review and Meta-Analysis. International journal of nursing studies. 2014 Jan 1;51(1):136-49. [DOI:10.1016/i.ijnurstu.2012.12.017] [PMID]

13. Ventura R, Quero MJ. Using Facebook in University Teaching: A Practical Case Study. Procedia-Social and Behavioral Sciences. 2013 Jul 4;83:1032-8. [DOI:10.1016/j.sbspro.2013.06.192]

14. Eger L. Is Facebook a Similar Learning Tool for University Students as LMS?. Procedia-Social and Behavioral Sciences. 2015 Aug 26;203:233-8. [DOI:10.1016/j.sbspro.2015.08.287]

15. Kadivar M, Seyedfatemi N, Zolfaghari M, Mehran A, Azizkhani L. The Effect of Virtual Education on Neonatal Nurses' Caring Ability at the Neonatal Intensive Care Unit. Journal of Pediatric Nursing. 2017 Apr 1;3(3):32-9. [DOI:10.21859/jpen-03036]

16. Hosseini MA, Ghahremani AR, Mohammadi Shahbolaghi F, Hamadzadeh S, Tamizi Z. The Advantages of Electronic Learning in Nursing Education: A Review study. Journal of Nursing Education. 2016 Feb 10;4(4):9-16.

17. Ghaffari M, Rakhshanderou S, Mehrabi Y, Tizvir A. Using Social Network of Telegram for Education on Continued Breastfeeding and Complementary Feeding of Children Among Mothers: A Successful Experience from Iran. International Journal of Pediatrics. $2017 \mathrm{Jul}$ 1;5(7):5275-86

18. Kordi M, Rashidi Fakari F, Mazlom R, Khadivarzadeh T, Akhlaghi F. Comparison of Web-Based Training, Simulation and Durability of Traditional Knowledge and Skills in the Management of Postpartum 
Hemorrhage Midwifery Students. J Obstetric Gynecol Iran. 2014;16(89):8-14.

19. Hashemi S, Salaree MM, Salaree M, Delavari AA, Khoshsima S. The Comparison of Learning Levels in Chemical Element Nursing with Three Approaches: Web-Based Electronics Training, Multi-Media Software Packages and Lecturing. Education Strategies in Medical Sciences. 2016 Apr 10;9(1):26-33.

20. Dianati M, Zaheri A, Talari HR, Deris F, Rezaei S. Intensive Care Nurses' Knowledge of Radiation Safety and Their Behaviors Towards Portable Radiological Examinations. Nursing and midwifery studies. 2014 Dec;3(4):1-5. [DOI:10.17795/nmsjournal23354] [PMID] [PMCID]

21. Shafi H, Ghayemiayn N, Amani N, Bezhani S, Kamali S. Survey of Knowledge of Nurses in Shahid Beheshti and Yahyanejad About Principles of Radiation Protection in Babol Iranian Journal of Surgery. 2016;24(2):71-82.

22. Alotaibi M, Al-Abdulsalam A, Bakir YY, Mohammed AM. Radiation Awareness Among Nurses in Nuclear Medicine Departments. Australian Journal of Advanced Nursing, The. 2015 Mar;32(3):25.

23. Alzubaidi MA, Mutairi HH, Alakel SM, Al Abdullah HA, Albakri IA, Alqahtani SF. Assessment of Knowledge and Attitude of Nurses Towards Ionizing Radiation During Radiography in Jeddah City, 2017. The Egyptian Journal of Hospital Medicine. 2017 Oct 1;69(7):2906-9. [DOI:10.12816/0042590]

24. Urushizaka M, Noto $Y$, Ogura N, Kitajima M, Nishizawa $Y$, Ichinohe $T$, Yamabe $H$. Changes in nurses' Impression of Radiation After Attending Educational Seminars on Radiation. Radiation Emergency Medicine. 2013 Aug;2:35-42.

25. Yurt A, Çavuşoğlu B, Günay T. Evaluation of Awareness on Radiation Protection and Knowledge About Radiological Examinations in Healthcare Professionals Who Use Ionized Radiation at Work. Molecular Imaging and Radionuclide Therapy. 2014 Jun;23(2):48-53. [DOI:10.4274/mirt.00719] [PMID] [PMCID]

26. Nasteizaei N, Hezare moghadam M. A Comprative Survey on Effects of Face to Face and Distanced Short Term Training Courses on Staff, psychological Empoverment Journal of Nursing and Midwifery Urmia University of Medical Sciences 2010;4(8):25-46. 